\title{
LETTER
}

\section{Urine biochemistry in acute kidney injury: are we moving in the right direction?}

\author{
Alexandre Toledo Maciel ${ }^{1,2^{*}}$ and Daniel Vitorio ${ }^{1}$ \\ See related research by Pons et al., http://ccforum.com/content/17/2/R56
}

We read with interest the article by Pons and colleagues [1] in a recent issue of Critical Care and we would like to ask them a few questions. They excluded patients 'for whom urine could not be collected according to the study protocol' [1]. What were the reasons for this - anuria, renal replacement therapy (RRT), ICU discharge or death? The authors said that there was no patient receiving RRT at the time of the study, but then they mentioned 14 patients requiring RRT in the first 24 hours. How many patients were excluded due to less than 72 hours of follow-up? Since acute kidney injury (AKI) diagnosis was mandatorily done on admission in order to define AKI reversal in the first 3 ICU days, what about patients who were 'no-AKI' on admission but developed AKI in these 3 days?

The authors evaluated urinary indices which are actually calculated variables, dependent on multiple measured parameters. In a pilot study [2], we demonstrated that urinary sodium $(\mathrm{NaU})$ was lower on admission in patients who developed AKI in the first 4 ICU days. We believe that sequential $\mathrm{NaU}$ measurement is useful, especially in the absence of diuretics, and that early AKI development is characterized by decreases in $\mathrm{NaU}$ which may precede increases in creatinine, in both transient and persistent AKI (unpublished data). These findings suggest that transient and persistent AKI are different magnitudes of the same pathophysiological process and not synonyms of functional/structural AKI [3]. This may partially explain the absence of discernment ability of the urinary indices. What was the time course of $\mathrm{NaU}$ in your three groups in the absence of diuretics? We believe that there is a role for urine biochemistry in AKI assessment and to exclude it from daily practice is the wrong direction.

\section{Authors' response \\ Bertrand Pons and Michael Darmon}

We thank Maciel and Vitorio for their comments and appreciate their interest in our work. We enrolled 202 patients, and 58 were excluded as consequences of missing urine samples or an early ICU discharge precluding patient classification.

Patients without AKI at the time of urine collection were considered 'no AKI' even if they developed AKI after day 1 . We fully agree that the rise in creatinine is delayed following renal injury and that some patients therefore might have been misclassified [4]. However, AKI was defined according to the Acute Kidney Injury

\footnotetext{
* Correspondence: alexandre.toledo@intensimed.com ${ }^{1}$ Intensimed Research Group, Intensive Care Unit, Hospital São Camilo, Av Pompéia 1178, São Paulo ZIP code 05024-000 SP, Brazil ${ }^{2}$ Intensive Care Unit, Department of Medical Emergencies, Hospital das Clínicas University of São Paulo, Av Dr Enéas de Carvalho Aguiar 255, São Paulo ZIP code 05403-010, Brazil
}

Network criteria of both urine output and serum creatinine, and this may have limited the risk of patient misclassification $[5,6]$.

Overall, 20 patients (21\%) without AKI at inclusion developed AKI between days 1 and 3. These patients had similar $\mathrm{NaU}$ concentration at inclusion to patients without AKI from inclusion to day 3: $77 \mathrm{mmol} / \mathrm{L}$ (40 to 120) versus $79 \mathrm{mmol} / \mathrm{L}$ (34 to 110$)(P=0.79)$. Similarly, fractional excretion of urea and fractional excretion of sodium or other urinary indices in this subgroup of patients were similar to those of patients without AKI from inclusion to day 3.

Lastly, NaU concentration at inclusion was similar across patient groups - $72 \mathrm{mmol} / \mathrm{L}$ (38 to 113) in patients without AKI, $55 \mathrm{mmol} / \mathrm{L}$ (24 to 84) in patients with transient AKI, and $64 \mathrm{mmol} / \mathrm{L}$ (35 to 99 ) in patients 
with persistent AKI at inclusion $(P=0.07)$ - or at later time points.

We agree with Maciel and Vitorio that further research in this field is welcome. However, the evidence suggests that urinary biochemistry indices should no longer be recommended routinely $[1,7]$.

\section{Abbreviations}

AKl: Acute kidney injury; NaU: Urinary sodium; RRT: Renal replacement therapy.

\section{Competing interests}

The authors declare that they have no competing interests.

Published: 15 Nov 2013

\section{References}

1. Pons B, Lautrette A, Oziel J, Dellamonica J, Vermesch R, Ezingeard E, Mariat C, Bernardin G, Zeni F, Cohen Y, Tardy B, Souweine B, Vincent F, Darmon M: Diagnostic accuracy of early urinary index changes in differentiating transient from persistent acute kidney injury in critically ill patients: multicenter cohort study. Crit Care 2013, 17:R56.

2. Maciel AT, Park M, Macedo E: Urinary electrolyte monitoring in critically ill patients: a preliminary, observational study. Rev Bras Ter Intensiva 2012, 24:236-245.

3. Schneider AG, Bellomo R: Urinalysis and pre-renal acute kidney injury: time to move on. Crit Care 2013, 17:141.

4. Waikar SS, Bonventre JV: Creatinine kinetics and the definition of acute kidney injury. J Am Soc Nephrol 2009, 20:672-679.

5. Mehta RL, Kellum JA, Shah SV, Molitoris BA, Ronco C, Warnock DG, Levin A: Acute Kidney Injury Network: report of an initiative to improve outcomes in acute kidney injury. Crit Care 2007, 11:R31.

6. Ralib AM, Pickering JW, Shaw GM, Endre ZH: The urine output definition of acute kidney injury is too liberal. Crit Care 2013, 17:R112.

7. Darmon M, Vincent F, Dellamonica J, Schortgen F, Gonzalez F, Das V, Zeni F, Brochard L, Bernardin G, Cohen Y, Schlemmer B: Diagnostic performance of fractional excretion of urea in the evaluation of critically ill patients with acute kidney injury: a multicenter cohort study. Crit Care 2011, 15:R178.

$10.1186 / \mathrm{cc} 13112$

Cite this article as: Maciel and Vitorio: Urine biochemistry in acute kidney injury: are we moving in the right direction?

Critical Care 2013, 17:459 